\title{
bla $_{\mathrm{KPC}}$ and $r m t B$ on a single plasmid in Enterobacter amnigenus and Klebsiella pneumoniae isolates from the same patient
}

\author{
J.-F. Sheng $\cdot$ J.-J. Li $\cdot$ S. Tu $\cdot$ Z.-K. Sheng $\cdot$ S. Bi $\cdot$ \\ M.-H. Zhu • X.-M. Shen $\cdot$ L.-J. Li
}

Received: 24 April 2011 / Accepted: 28 October 2011 /Published online: 12 January 2012

(C) The Author(s) 2012. This article is published with open access at Springerlink.com

\begin{abstract}
Enterobacter amnigenus (EA76) and Klebsiella pneumoniae (KP76) isolates with multidrug-resistant (MDR) patterns were identified from the same patient in the neurosurgery department of our hospital. An outbreak of MDR $K$. pneumoniae had also occurred in this department. To characterize the resistance mechanism and molecular epidemiology of these isolates, sequential experiments including antimicrobial susceptibility testing, polymerase chain reaction (PCR), plasmid analysis, pulsed field gel electrophoresis (PFGE), and multilocus sequence typing (MLST) were performed. EA76 and KP76 were resistant to all of the antibiotics tested, except colistin and tigecycline. bla $a_{\mathrm{KPC}-2}, b l a_{\mathrm{TEM}-1}, b l a_{\mathrm{SHV}-12}$, $b l a_{\mathrm{CTX}-\mathrm{M}-3}, b l a_{\mathrm{CTX}-\mathrm{M}-14}$, and $r m t B$ genes were identified in both isolates, with $b l a_{\mathrm{KPC}-2}, b l a_{\mathrm{TEM}-1}, b l a_{\mathrm{CTX}-\mathrm{M}-14}$, and $r m t B$ being co-carried on one plasmid in each isolate. Further analysis showed different restriction patterns between the two KPC-carrying plasmids. Of the 11 carbapenem-resistant isolates found in the outbreak, all
\end{abstract}

\footnotetext{
J.-F. Sheng • J.-J. Li $\cdot$ S. Bi $\cdot$ M.-H. Zhu $\cdot$ X.-M. Shen •

L.-J. Li $(\bowtie)$

State Key Laboratory for Diagnosis and

Treatment of Infectious Disease,

First Affiliated Hospital, College of Medicine,

Zhejiang University,

Hangzhou 310003 Zhejiang, People's Republic of China

e-mail: 1jli@zju.edu.cn
}

\section{S. Tu}

First Affiliated Hospital of Zhejiang Chinese Medical University, Hangzhou, People's Republic of China

Z.-K. Sheng

Children's Hospital, Zhejiang University School of Medical College,

Hangzhou, People's Republic of China were resistant to all of the $\beta$-lactams tested, with $63.64 \%$ (7/11) also exhibiting resistance to aminoglycosides and $72.73 \%(8 / 11)$ exhibiting resistance to quinolones. PCR analysis and molecular typing of the $11 \mathrm{~K}$. pneumoniae strains revealed that the seven aminoglycoside-resistant isolates shared the same antibiotic-resistant gene pattern and identical or one-band-difference PFGE profiles relative to KP76. In addition, all of the eight aminoglycoside-resistant isolates, including KP76, belonged to the national epidemic clone ST11. The overall results indicate the emergence of E. amnigenus and outbreak of ST11 K. pneumoniae, with both co-harboring $b l a_{\mathrm{KPC}}$ and $r m t B$ genes on a single plasmid in our neurosurgery wards.

\section{Introduction}

Carbapenems are considered to be the first-line therapy in the treatment of serious infections caused by extended-spectrum $\beta$-lactamase (ESBL)-producing Enterobacteriaceae [1]. Therefore, the emergence and prevalent dissemination of carbapenem-resistant Enterobacteriaceae presented a serious therapeutic challenge. Klebsiella pneumoniae carbapenemase (KPC), a member of the class A carbapenemase family, can hydrolyze all $\beta$-lactam molecules. Since it was first reported in a $K$. pneumoniae isolate in 2001 [2], KPC has disseminated widely among nosocomial pathogens, especially Enterobacteriaceae, and has become the most frequent class A carbapenemase worldwide [1]. Fortunately, most KPCproducing isolates are still susceptible to one or more aminoglycoside antibiotics [3, 4].

Since 2003, the production of $16 \mathrm{~S}$ rRNA methylase has been reported to be a new mechanism of aminoglycoside 
resistance. So far, seven types of methylases have been identified (ArmA, RmtA, RmtB, RmtC, RmtD, RmtE, and NpmA) [5-7]. Their presence could confer a panresistance pattern to clinically useful aminoglycosides. The co-existence of $16 \mathrm{~S}$ rRNA methylases and various ESBLs in Enterobacteriaceae has been reported from time to time $[5,7]$. Recently, the co-existence of $16 \mathrm{~S}$ rRNA methylase, such as ArmA and RmtB, has also been reported in KPC-producing pathogens [8,9]. This co-existence is quite alarming because additional high-level resistance to aminoglycosides in KPC-producing isolates and their potential spread would strongly limit the therapeutic options.

In previous publications, methylase genes and $b l a_{\mathrm{KPC}}$ were reported to be mostly located on different plasmids $[8,9]$. Only Jiang et al. have reported a $K$. pneumoniae plasmid co-carrying $b l a_{\mathrm{KPC}-2}$ and armA to date [10]. Moreover, when their coexistence is observed, it is mainly confined to a single isolate, and there has been no epidemic reported to date.

In the present study, we describe a multiresistant Enterobacter amnigenus isolate and a $K$. pneumoniae isolate from the same patient, both co-carrying $b l a_{\mathrm{KPC}-2}$ and $r m t B$ genes on a single plasmid. Further studies revealed that the multidrug-resistant (MDR) $K$. pneumoniae co-harboring $b l a_{\mathrm{KPC}-2}$ and $r m t B$ had disseminated clonally in our neurosurgery department. To our knowledge, this is the first report of the detection of $b l a_{\mathrm{KPC}}$ and $r m t B$ in E. amnigenus, and also the first documenting of the emergence and outbreak of MDR $K$. pneumoniae co-carrying $b l a_{\mathrm{KPC}}$ and $r m t B$ on a single plasmid.

\section{Materials and methods}

\section{Bacterial strains}

Carbapenem-resistant E. amnigenus (EA76) and K. pneumoniae (KP76) and an additional 11 non-duplicate carbapenem-resistant $K$. pneumoniae isolates were collected from the neurosurgery department of The First Affiliated Hospital of the School of Medicine, Zhejiang University, China, from April 2010 to December 2010. EA76 and KP76 were isolated from the same patient simultaneously, with EA76 from blood samples and KP76 from fecal specimens. The other 11 carbapenem-resistant $K$. pneumoniae strains were obtained from the following specimens: lower respiratory tract (LRT) $(n=7)$, upper respiratory tract (URT) $(n=1)$, blood $(n=1)$, cerebrospinal fluid (CSF) $(n=1)$, and secretion $(n=1)$. Azide-resistant Escherichia coli J53 and E. coli DH5 $\alpha$ cells (TAKARA, China) were used as recipients in conjunction and transformation experiments, respectively.
Antimicrobial susceptibility testing

Minimal inhibitory concentrations (MICs) of various antibiotics for KP76, EA76, and their E. coli transformants were determined with E-test strips according to the manufacturer's instructions (AB Biodisk, Solna, Sweden). The MICs for the other 11 carbapenem-resistant $K$. pneumoniae isolates were performed by the agar dilution method, as described in the guidelines from the Clinical and Laboratory Standards Institute (CLSI) [11]. The susceptibility results were interpreted according to the CLSI criteria [11]. For tigecycline, the US Food and Drug Administration (FDA) breakpoint values for Enterobacteriaceae were used (susceptible: $\leq 2 \mathrm{mg} / \mathrm{L}$; resistant: $\geq 8 \mathrm{mg} / \mathrm{L}$ ), and a concentration of $4 \mathrm{mg} / \mathrm{L}$ was used as the breakpoint of resistance for colistin [12]. E. coli ATCC 25922 was used as a quality control strain.

Conjugation, transformation, and plasmid analysis

Repeated attempts to transfer carbapenem resistance from EA76 and KP76 to sodium azide-resistant $E$. coli strain J53 by a mixed-broth mating procedure were performed. MuellerHinton agar (MHA) containing $0.5 \mathrm{mg} / \mathrm{L}$ meropenem and $200 \mathrm{mg} / \mathrm{L}$ sodium azide was used to select the transconjugants. Plasmids of EA76 and KP76 were extracted with the QIAGEN Plasmid Midi Kit (Qiagen, Germany) and transformed into competent E. coli DH5 $\alpha$ (TAKARA, China). MHA plates containing $1 \mathrm{mg} / \mathrm{L}$ meropenem were used to select transformants. KP76-T and EA76-T, confirmed as $b l a_{\mathrm{KPC}}$-positive by polymerase chain reaction (PCR) analysis, were designated as E. coli transformants of KP76 and EA76, respectively. The plasmids in EA76-T and KP76$\mathrm{T}$ were extracted with the QIAGEN Plasmid Midi Kit and digested by BamHI, SmaI, and EcoRI (TAKARA, China). Plasmid DNAs and the digestion products were separated by gel electrophoresis in $0.8 \%$ agarose at $140 \mathrm{~V}$ for $2 \mathrm{~h}$.

\section{PCR screening and DNA sequencing}

Total DNAs were prepared with the boiling method as described previously [13], and used as templates for PCR amplification. Amplification primers for $b l a_{\mathrm{KPC}}, b l a_{\mathrm{TEM}}$,

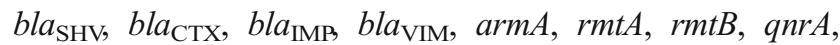
$q n r B$, and $q n r S$ were used as described previously [7, 14-16]. All PCR products were sequenced by the dideoxynucleotide chain-termination method by ABI 377 (ABI, USA) and the sequences were compared with the nucleotide sequences from GenBank (http://www.ncbi.nlm.nih.gov/blast).

Pulsed field gel electrophoresis (PFGE)

Genomic DNAs prepared from KP76 and the other $11 \mathrm{~K}$. pneumoniae strains were embedded in agarose gel plugs. 
After digestion with restricted enzyme XbaI (TAKARA, China), DNA fragments were separated using a CHEFMapper XA PFGE system (Bio-Rad, USA) for $23 \mathrm{~h}$ at $6 \mathrm{~V} / \mathrm{cm}$ and $14^{\circ} \mathrm{C}$, with a pulse angle of $120^{\circ}$ and pulse times from $5 \mathrm{~s}$ to $35 \mathrm{~s}$. PFGE profiles were analyzed visually [17].

\section{Multilocus sequence typing (MLST)}

Multilocus sequence typing (MLST) with seven housekeeping genes (gapA, infB, mdh, pgi, phoE, rpoB, and tonB) was carried out for all $K$. pneumoniae isolates, including KP76, according to protocols provided on the MLST website for $K$. pneumoniae (http://www.pasteur.fr/recherche/genopole/PF8/ $\mathrm{mlst} /$ Kpneumoniae.html).

\section{Results}

Antimicrobial susceptibility testing

EA76 and KP76 were resistant to almost all of the antimicrobial agents tested, including cephalosporins, imipenem, meropenem, amikacin, gentamicin, and ciprofloxacin, but they were susceptible to colistin and tigecycline (Table 1). Their E. coli transformants gained a $\beta$-lactam resistance pattern with elevated MICs of carbapenems. The MIC of ertapenem for EA76-T was as high as $16 \mathrm{mg} / \mathrm{L}$. In addition, aminoglycoside resistance was also transferred to EA76-T and KP76-T.

The other 11 carbapenem-resistant $K$. pneumoniae isolates showed complete resistance to all of the $\beta$-lactams tested as well. Of them, eight were also resistant to ciprofloxacin and seven were highly resistant to amikacin. Moreover, all of the seven amikacin-resistant isolates were classified into the ciprofloxacin-resistant group. All of the 11 isolates were susceptible to colistin and tigecycline (Table 1).

Conjugation, transformation, and plasmid analysis

Repeated attempts to transfer carbapenem resistance from EA76 and KP76 to sodium azide-resistant E. coli strain J53 were unsuccessful. Two plasmids were extracted from EA76 and KP76, respectively. The larger plasmid extracted from each strain (both $\sim 54 \mathrm{~kb}$ ) was transformed into $E$. coli DH5 $\alpha$ (Fig. 1a). Restriction analysis of plasmid DNAs showed different patterns between the two transformants, EA76-T and KP76-T (Fig. 1b).

PCR screening and DNA sequencing

EA76 and KP76 were positive for $b l a_{\mathrm{KPC}-2}, b l a_{\mathrm{TEM}-1}, b l a_{\mathrm{SHV}-12}$, $b l a_{\mathrm{CTX}-\mathrm{M}-3}, b l a_{\mathrm{CTX}-\mathrm{M}-14}$, and $r m t B$ genes, whereas EA76-T and KP76-T were positive for $b l a_{\mathrm{KPC}-2}, b l a_{\mathrm{TEM}-1}, b l a_{\mathrm{CTX}-\mathrm{M}-14}$, and $r m t B$ genes. This indicates that $b l a_{\mathrm{KPC}-2}$ co-existed with $b l a_{\mathrm{TEM}-1}, b l a_{\mathrm{CTX}-\mathrm{M}-14}$, and $r m t B$ on a single plasmid in both KP76 and EA76 strains. Of the other $11 \mathrm{~K}$. pneumoniae isolates, all seven amikacin-resistant isolates shared an identical resistance gene profile as KP76, whereas two of the four amikacin-susceptible isolates harbored all of the genes found in KP76, with the exception of $r m t B$. The remaining two amikacin-susceptible isolates (KP45 and KP54) harbored $b l a_{\mathrm{VIM}-1}$ carbapenemase gene rather than $b l a_{\mathrm{KPC}}$. KP45 also carried $b l a_{\mathrm{TEM}-1}$ and $b l a_{\mathrm{CTX}-\mathrm{M}-10}$, while KP54 carried $b l a_{\mathrm{SHV}-12}$ and bla $a_{\mathrm{CTX}-\mathrm{M}-56}$. No $q n r$ genes were detected in any of the screened isolates.

\section{PFGE}

PFGE profile analysis revealed that 9 of the $11 \mathrm{~K}$. pneumoniae isolates had identical or one-band-difference patterns relative to KP76. The remaining two isolates (KP45 and KP54), which were positive for bla ${ }_{\mathrm{VIM}-1}$, had distinct PFGE patterns (Fig. 2).

\section{MLST}

MLST showed three sequence types (STs) based on the analysis of the seven housekeeping genes in the $12 \mathrm{~K}$. pneumoniae isolates. Of the three sequence types, ST11 was the dominant type and was detected in ten isolates, including KP76. The remaining two isolates, KP45 and KP54, were found to belong to ST494 and ST23, respectively. These MLST results were in accordance with our PFGE findings. The nine ST11 isolates belonged to one PFGE type, and the ST494 and ST23 isolates belonged to two distinct PFGE types.

\section{Discussion}

To our knowledge, this is the first report of an $E$. amnigenus isolate that is resistant to both carbapenems and aminoglycosides. E. amnigenus is a Gram-negative aerobic bacillus of the family Enterobacteriaceae. They are ubiquitous in nature and have been occasionally isolated from clinical specimens, such as sputum, wound, blood, and feces [18]. In 2006, an epidemic of post-cataract surgery endophthalmitis was reported to be caused by this pathogen in India [19]. E. amnigenus has been reported to be fully susceptible to almost all antimicrobial agents that are generally active against Enterobacteriaceae, including aminoglycosides, most $\beta$-lactams, fluoroquinolones, chloramphenicol, and nitrofurantoin [20]. Here, we reported an E. amnigenus isolate co-carrying $b l a_{\mathrm{KPC}-2}, b l a_{\mathrm{TEM}-1}$, $b l a_{\mathrm{SHV}-12}, b l a_{\mathrm{CTX}-\mathrm{M}-3}, b l a_{\mathrm{CTX}-\mathrm{M}-14}$, and $r m t B$ genes, with 


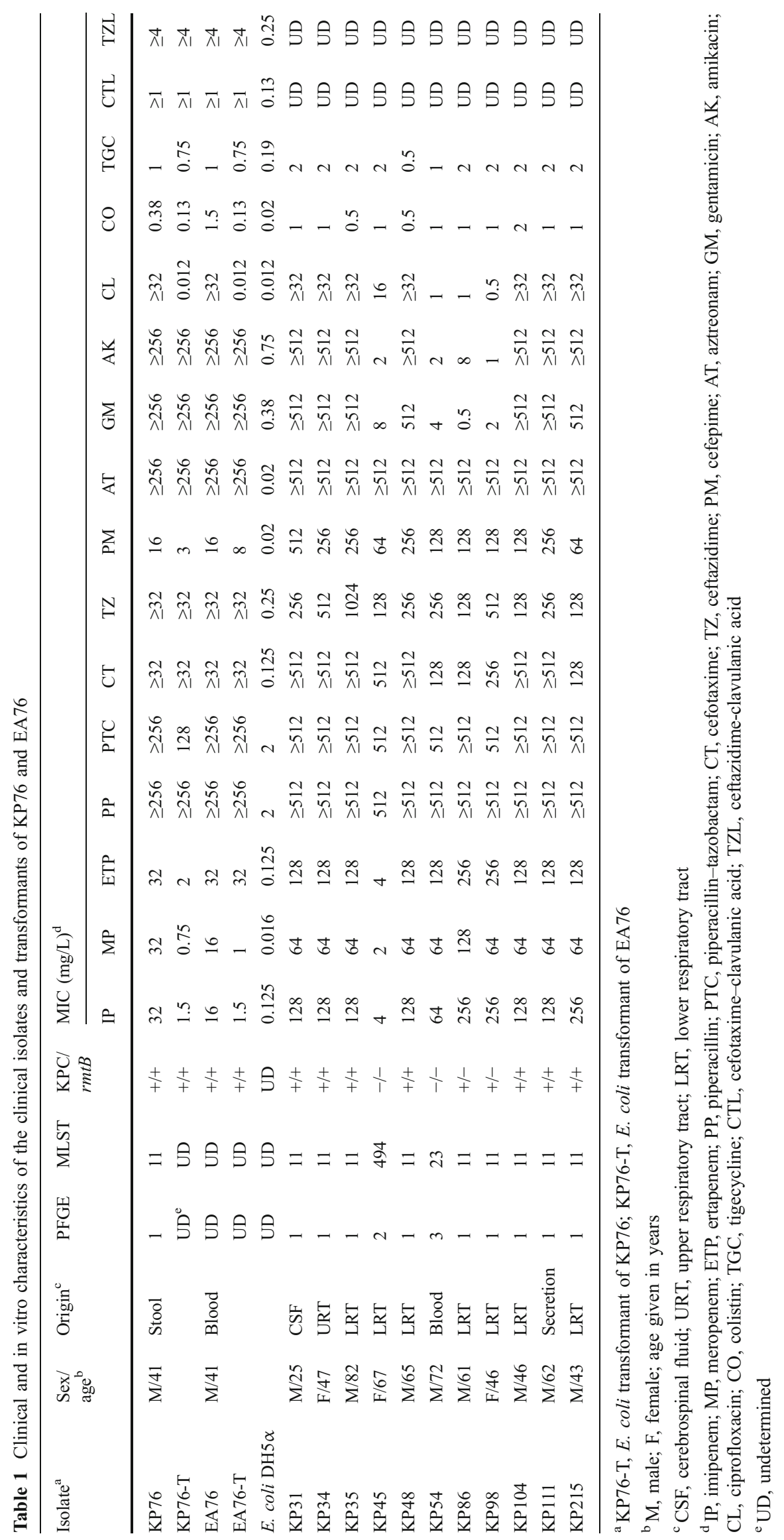


Fig. 1 a Plasmid DNAs profiles of EA76, KP76, EA76-T, and KP76-T. M, E. coli V517 (used as a standard for plasmid size); lane 1, EA76; lane 2, KP76; lane 3, EA76-T; and lane 4, KP76-T. b Restriction patterns of Klebsiella pneumoniae carbapenemase (KPC)-producing plasmid DNAs from EA76-T and KP76-T. $M, 1-\mathrm{kb}$ DNA ladder; lanes 1,3 , and 5, EA76-T; lanes 2, 4, and 6, KP76-T. Plasmid DNAs were digested with BamHI, SmaI, and EcoRI

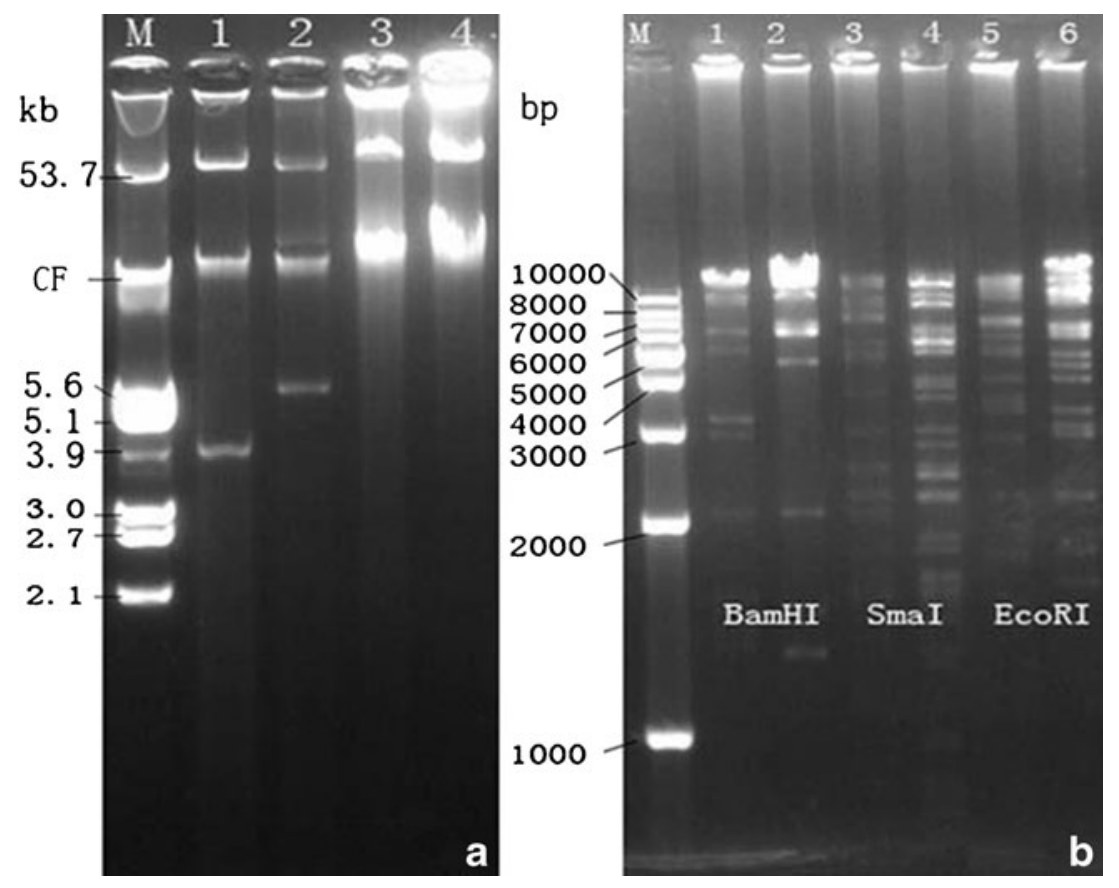

$b l a_{\mathrm{KPC}-2}, b l a_{\mathrm{TEM}-1}, b l a_{\mathrm{CTX}-\mathrm{M}-14}$, and $r m t B$ on the same plasmid. This isolate was resistant to almost all of the antibiotics tested, except tigecycline and colistin. Therefore, antibiotic regimens for infections involving this pathogen would become rather limited if this

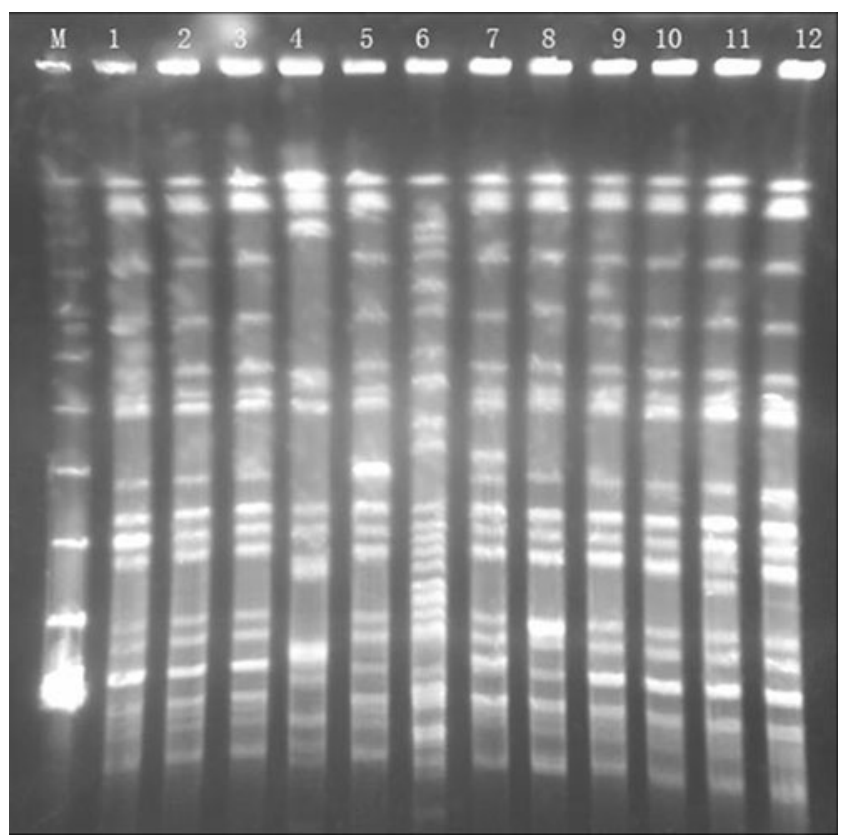

Fig. 2 Pulsed field gel electrophoresis (PFGE) of XbaI-digested DNAs of $K$. pneumoniae isolates from our neurosurgery wards. $M, \lambda$ DNA ladder; lane 1, KP31; lane 2, KP34; lane 3, KP35; lane 4, KP45; lane 5, KP48; lane 6, KP54; lane 7, KP86; lane 8, KP98; lane 9, KP104; lane 10, KP111; lane 11, KP215; and lane 12, KP76 multiresistant isolate were to become disseminated. In addition, due to their presence in the environment, the acquisition and accumulation of resistance determinants could make E. amnigenus a potential natural reservoir for these determinants.

The EA76 and KP76 isolates that were co-carrying $b l a_{\mathrm{KPC}}$ and $r m t B$ were from the same patient. Their KPC-producing plasmids were of the same size and shared an identical resistance determinant profile. Nevertheless, restriction analysis of the two KPC-producing plasmids showed different patterns. Further screening of carbapenem-susceptible E. amnigenus isolates from fecal specimens of the same patient were unsuccessful. These results together argue against our initial expectation that EA76 obtained its $b l a_{\mathrm{KPC}}$ gene directly from KP76 via the in vivo transmission of a co-harboring plasmid as described previously [21]. It is possible that EA76 acquired the $b l a_{\mathrm{KPC}}$ gene via the mobility of transposon. Since $b l a_{\mathrm{KPC}}$ genes were reported to be located within a roughly 10-kb Tn-3-type transposon, Tn4401, which can facilitate their mobility between different clones of the same species or even between clones of different genera [1]. Or, perhaps most likely, EA76 could have acquired the KPC-producing plasmid elsewhere, given that KPC-producing $K$. pneumoniae were known to be disseminated widely in our hospital before the isolation of EA76 (data unpublished).

We found that $7(63.64 \%)$ of the 11 other carbapenemresistant $K$. pneumoniae isolates from our neurosurgery wards were also highly resistant to aminoglycosides. PCR analysis revealed that these seven isolates had identical 
antimicrobial gene profiles as KP76. PFGE revealed that six of these seven isolates shared a common identical PFGE profile with KP76, whereas the remaining isolate showed a one-band-difference profile (Fig. 2). MLST analysis showed that all seven of these isolates together with KP76 belonged to ST11, which is also the dominant clone of KPC-producing K. pneumoniae in China [22]. These observations strongly suggest that the ST11 $K$. pneumoniae isolates containing $b l a_{\mathrm{KPC}-2}$ and $r m t B$ on a single plasmid had disseminated clonally in our neurosurgery wards. Two of the remaining four $K$. pneumoniae isolates fell into the same PFGE type as KP76, and belonged to the ST11 clone as well. They carried the same resistance genes as KP76, except $r m t B$. This could partly indicate that $r m t B$ could have disseminated via the mobilization of transposon or other transposable elements between $K$. pneumoniae isolates as well, since $r m t B$ has been reported to be located adjacent to mobile genetic elements $[5,13]$. The other two remaining $K$. pneumoniae isolates carried totally different resistance genes and belonged to distinct PFGE and MLST types.

In our study, 9/12 (75\%) carbapenem-resistant $K$. pneumoniae isolates showed ciprofloxacin resistance, including all eight KPC-RmtB co-producing isolates. However, no $q n r$ genes were identified in any of the $K$. pneumoniae isolates. Quinolone resistance in these strains could have been mediated by mutations of the gyrase and topoisomerase IV genes or by efflux pump mechanisms.

In conclusion, here, we have reported an E. amnigenus strain and a $K$. pneumoniae strain that each co-carried $b l a_{\mathrm{KPC}-2}$ and $r m t B$ on a single plasmid; nevertheless, the two plasmids were different. Further studies revealed that the MDR ST11 K. pneumoniae co-carrying $b l a_{\mathrm{KPC}-2}$ and $r m t B$ had disseminated widely in our neurosurgery wards. The co-carriage of various antibiotic resistance determinants on one plasmid can provide survival advantages and evolutionary benefits to bacteria in an antibiotic-rich environment, and facilitate their wide spread. In addition, it can also facilitate the co-transmission of various competent resistance determinants among different pathogens. These observations, together with the fact that few therapeutic options are available for these infections, compel us to take urgent actions to contain this outbreak and the persistent spread of KPC-RmtB co-producing $K$. pneumoniae in the hospital setting.

\footnotetext{
Acknowledgments This work was supported by the National Basic Research Program of China (no. 2007CB513004). We thank the platform Genotyping of Pathogens and Public Health (Institut Pasteur) for coding the MLST alleles and profiles.
}

Disclosure statement No competing financial interests exist.
Open Access This article is distributed under the terms of the Creative Commons Attribution Noncommercial License which permits any noncommercial use, distribution, and reproduction in any medium, provided the original author(s) and source are credited.

\section{References}

1. Nordmann P, Cuzon G, Naas T (2009) The real threat of Klebsiella pneumoniae carbapenemase-producing bacteria. Lancet Infect Dis 9:228-236

2. Yigit H, Queenan AM, Anderson GJ, Domenech-Sanchez A, Biddle JW, Steward CD, Alberti S, Bush K, Tenover FC (2001) Novel carbapenem-hydrolyzing beta-lactamase, KPC-1, from a carbapenem-resistant strain of Klebsiella pneumoniae. Antimicrob Agents Chemother 45:1151-1161

3. Giakkoupi P, Papagiannitsis CC, Miriagou V, Pappa O, Polemis M, Tryfinopoulou K, Tzouvelekis LS, Vatopoulos AC (2011) An update of the evolving epidemic of bla $a_{\mathrm{KPC}-2}$-carrying Klebsiella pneumoniae in Greece (2009-10). J Antimicrob Chemother 66:1510-1513

4. Souli M, Galani I, Antoniadou A, Papadomichelakis E, Poulakou G, Panagea T, Vourli S, Zerva L, Armaganidis A, Kanellakopoulou K, Giamarellou H (2010) An outbreak of infection due to beta-lactamase Klebsiella pneumoniae carbapenemase 2producing $K$. pneumoniae in a Greek University Hospital: molecular characterization, epidemiology, and outcomes. Clin Infect Dis 50:364-373

5. Doi Y, Arakawa Y (2007) 16S ribosomal RNA methylation: emerging resistance mechanism against aminoglycosides. Clin Infect Dis 45:88-94

6. Wachino J, Shibayama K, Kurokawa H, Kimura K, Yamane K, Suzuki S, Shibata N, Ike Y, Arakawa Y (2007) Novel plasmidmediated 16S rRNA m1A1408 methyltransferase, NpmA, found in a clinically isolated Escherichia coli strain resistant to structurally diverse aminoglycosides. Antimicrob Agents Chemother 51:4401-4409

7. Zhou Y, Yu H, Guo Q, Xu X, Ye X, Wu S, Guo Y, Wang M (2010) Distribution of 16S rRNA methylases among different species of Gram-negative bacilli with high-level resistance to aminoglycosides. Eur J Clin Microbiol Infect Dis 29:1349-1353

8. Zacharczuk K, Piekarska K, Szych J, Zawidzka E, Sulikowska A, Wardak S, Jagielski M, Gierczynski R (2011) Emergence of Klebsiella pneumoniae coproducing KPC-2 and 16S rRNA methylase ArmA in Poland. Antimicrob Agents Chemother 55:443-446

9. Wu Q, Liu Q, Han L, Sun J, Ni Y (2010) Plasmid-mediated carbapenem-hydrolyzing enzyme KPC-2 and ArmA 16S rRNA methylase conferring high-level aminoglycoside resistance in carbapenem-resistant Enterobacter cloacae in China. Diagn Microbiol Infect Dis 66:326-328

10. Jiang Y, Yu D, Wei Z, Shen P, Zhou Z, Yu Y (2010) Complete nucleotide sequence of Klebsiella pneumoniae multidrug resistance plasmid pKP048, carrying bla KPC-2 $_{\text {, }} l a_{\mathrm{DHA}-1}, q n r B 4$, and armA. Antimicrob Agents Chemother 54:3967-3969

11. Clinical Laboratory and Standards Institute (CLSI) (2010) Performance Standards for Antimicrobial Susceptibility Testing: M100-S20-U. CLSI, Wayne, PA, USA

12. Gales AC, Reis AO, Jones RN (2001) Contemporary assessment of antimicrobial susceptibility testing methods for polymyxin B and colistin: review of available interpretative criteria and quality control guidelines. J Clin Microbiol 39:183-190

13. Yu FY, Yao D, Pan JY, Chen C, Qin ZQ, Parsons C, Yang LH, Li QQ, Zhang XQ, Qu D, Wang LX (2010) High prevalence of plasmid-mediated 16S rRNA methylase gene $r m t B$ among Escherichia coli clinical isolates from a Chinese teaching hospital. BMC Infect Dis 10:184 
14. Yamane K, Wachino J, Doi Y, Kurokawa H, Arakawa Y (2005) Global spread of multiple aminoglycoside resistance genes. Emerg Infect Dis 11:951-953

15. Navon-Venezia S, Chmelnitsky I, Leavitt A, Carmeli Y (2008) Dissemination of the CTX-M-25 family betalactamases among Klebsiella pneumoniae, Escherichia coli and Enterobacter cloacae and identification of the novel enzyme CTX-M-41 in proteus mirabilis in Israel. J Antimicrob Chemother 62:289-295

16. Cattoir V, Poirel L, Rotimi V, Soussy CJ, Nordmann P (2007) Multiplex PCR for detection of plasmid-mediated quinolone resistance $q n r$ genes in ESBL-producing enterobacterial isolates. J Antimicrob Chemother 60:394-397

17. Tenover FC, Arbeit RD, Goering RV, Mickelsen PA, Murray BE, Persing DH, Swaminathan B (1995) Interpreting chromosomal DNA restriction patterns produced by pulsed-field gel electrophoresis: criteria for bacterial strain typing. J Clin Microbiol $33: 2233-2239$
18. Corti G, Mondanelli N, Losco M, Bartolini L, Fontanelli A, Paradisi F (2009) Post-traumatic infection of the lower limb caused by rare Enterobacteriaceae and Mucorales in a young healthy male. Int J Infect Dis 13:e57-e60

19. Korah S, Braganza A, Jacob P, Balaji V (2007) An "epidemic" of post cataract surgery endophthalmitis by a new organism. Indian $\mathrm{J}$ Ophthalmol 55:464-466

20. Stock I, Wiedemann B (2002) Natural antibiotic susceptibility of Enterobacter amnigenus, Enterobacter cancerogenus, Enterobacter gergoviae and Enterobacter sakazakii strains. Clin Microbiol Infect 8:564-578

21. Goren MG, Carmeli Y, Schwaber MJ, Chmelnitsky I, Schechner V, Navon-Venezia S (2010) Transfer of carbapenem-resistant plasmid from Klebsiella pneumoniae ST258 to Escherichia coli in patient. Emerg Infect Dis 16:1014-1017

22. Qi Y, Wei Z, Ji S, Du X, Shen P, Yu Y (2011) ST11, the dominant clone of KPC-producing Klebsiella pneumoniae in China. J Antimicrob Chemother 66:307-312 